\title{
Analysis on the Changes in Consumer Behavior and Marketing Countermeasure
}

\author{
Haiyu Wang \\ Zhengzhou Normal University, Zhengzhou, 450044, Henan, China
}

\begin{abstract}
Currently, there's a huge change in the media use habit, demand and route to get the information for the consumers, and the right of consumers to release information is mostly realized, indicating an actual return of consumer sovereignty. In such a background, it is undoubtedly the best choice for the marketing of enterprise brand to focus on the target people, manage the client relation and increase the socialized videos.
\end{abstract}

Key words. consumer behavior; fragmentation; target people; opinion leader

\section{Introduction}

The development of science brought about a new marketing mode for the enterprise, and meanwhile the purchase behavior, purchase mind and purchase mode of consumer also experienced a new change. The emergence of On-line shopping is a comprehensive reflection of the changes in consumer's purchase behavior. It greatly reduces the costs of consumers and improves the perceived value for the customers. The personalized demand, convenience demand and recognized mind of consumers have been satisfied to the largest degree. To improve the marketing effect, the enterprise shall make some adjustment in the marketing strategy to be adapted to the changes in the consumer behavior and guide the consumer demands to demand to a higher level.

\section{Changes in consumer behavior}

\subsection{Changes in media use habit}

The popularity of $3 \mathrm{C}$ product (Computer, Communication \& Consumer Electronics) is changing the life of each consumer. In the pre-mobile terminal period, the consumers receive the external information at home, in the office, car or other fixed positions through TV, network and newspaper. But things had greatly changed during 2012-2013. From desktop to laptop, wire to wireless and mobile phone to tablet, the changes of media patterns make the consumers also change their use habits in time, space and content. In time, the users develop from concentrating on the night in traditional PC era to any spare time; In space, the use scenarios of users expand from home and office in traditional PC era to outdoor, transportation, recreational facility and other spaces, and they use different media tools for entertainment, chatting, shopping, etc.; 
Accordingly, the users start to have different demands and habits about different tools, so the media is further divided.

\subsection{Changes in demand}

The post 90 consumers are currently the main consumers. They grow with the fragmentation communication era, the personalized and point-to-point information communication mode are what the young people focus on. In terms of information obtainment, social communication or shopping, the smart mobile phone and tablet have become their channels to obtain the information, and this demand trend will be developed in vertical direction.

The consumer motivation of demand on convenience, novelty, fashion and conformity is becoming obvious. Quick lifestyle, crowded traffic, shortage of parking position and noisy shopping mall have become the reason why the people are fed up with shopping in the shopping mall or retail market. They prefer the convenient, fast, free-of-energy on-line purchase pattern. Furthermore, the on-line shopping has become a new fashion for consumption. The white collars of the age 18-35 are the main group for shopping. We can still remember the double eleven electric business battle last year. The on-line shopping involves everything in life from garment, book to large home appliance and car.

Currently, the explosive growth of mobile Internet is deeply changing the industrial ecological environment, as well as the lifestyle and demands on product and service of consumption. The socialized media are bringing a new platform of consumption with personality, low costs and convenience, and also exploit a commercial space with boundless possibility for the enterprises.

\subsection{Changes in the routes to get the information}

With the ever development of socialized media, there are more flexible routes for consumers to get the information. The dominant position of commercial and public sources have been gradually replaced by the individual and experience sources. The consumers will not only listen to the advertisement and introduction from salesmen. Instead, they consider the experience and assessment from others in the socialized media as the decisive factors affecting the purchase decision. An investigation in Facebook, a famous American social network, shows $75 \%$ of American consumers will refer to the comments on Facebook before purchasing, and half of the visited objectives will try out a new brand if it's recommended in the socialized media. The new media gradually and silently change the route for consumers to get the information and affect their decision and purchase behavior.

\section{New strategy for brand marketing}

\subsection{Concentrate on target people}

The largest reform the socialized media brought for the marketing is to actually establish a longterm interactive relation, namely familiarity, mutual understanding, mutual care, constant communication, etc.. If a brand is expected to improve its concentration degree of the target people on our products or services by marketing in the socialized media, there are four aspects that need to be focused on, namely accurate positioning to see through the target people, light the emotion to activate the expression of consumers, interference of opinion leader to improve the influence and constant communication to prolong the enthusiasm.

Accurate positioning to see through the target people. The brand party shall accurately position the target people, plan the activity theme, style and expression skills of communication language according to many of their features from the personality to lifestyle AIO mode, from brand preference to self-concept, and to their beloved communication language. A clear audience's 
psychology and behavior analysis also pave the road before the further discussion of socialized media.

Light the emotion to activate the expression of consumers. The brand sets an opening topic according to the features and preference of target people. It grants consumers more space for imagination and expression while getting closer to them. In the socialized media, a topic that produces resonance among the consumer is required as they can and want to say something about it. The communication context impossibly to be realized in traditional media, however, can be easily created with the help of new media. The consumer will automatically get closer to the brand if their emotions have been lit.

Interference of opinion leader to improve the influence. In the actual life, the opinion leader is very popular, so they can still be very powerful and controllable in the social communication media. According to the opinion of Shengyi Liu in Tencent, the Internet users are generally divided into four classes, namely influencer, responder, participator and passive information receiver in order, from which we can see the influence and status of opinion leader in the socialized structure of Internet. The opinion leader can activate more on-line users to participate in the network discussion, which is called the ripple effect, a huge influence.

Constant communication to prolong the enthusiasm. Using the influence of opinion leader to blow up the activity is just a start. If the brand part can constantly follow up and add new things according to the hot topic among the net friends, it will definitely maintain the enthusiasm of the whole activity rather than a flash in the pan.

\subsection{Management of customer relation}

Management of client relation is to focus on the management of consumers, communicate with the client, get to know the demands of consumers in a timely manner, analyze and constantly optimize the product and marketing promotion. The management measures are monitor, making up topics, rectification and refuting rumors. The principle of communication is democracy and freedom. It is better if the enterprises are less involved as the control and dominant position is not advisable. The main participators of social communication media master the network dialog, while the customers generally use these tools prior to the companies. So, if the company is involved, it shall be ready to act more flexibly, because the utility value of a social communication media will be lower if the dialog is controlled more strictly. In the marketing process of socialized media, the timeliness is an important feature. We shall timely collect the feedback from the consumer, understand their demands and provide the products and services they want. The enterprise may set some special staff in the marketing department to be responsible for network marketing, constantly communicate with the on-line consumers, focus on what they concentrate on and the development direction of topic, and collect information to provide a basis of marketing decision for the enterprise.

The traditional marketing promotion mainly includes TV, newspaper, portal website and other advertisements that circulate the product information in a single way to attract the client, and the rate of return is low. The socialized media tends to establish a communication platform, while the enterprise focuses more on the circulation of business concept, brand story, activity and other similar information to maintain the customer relation.

\subsection{Add socialized videos}

Video has become the first application on the Internet. Ai Rui seeks advice shows the number of Chinese network video users hits 350 million, with $65.1 \%$ of permeability. Such a large group of people are meant to be concentrated by the advertisement. The video media originally functioned as a supplement for TV. With the change of consumer's use habit, the socialized media video is needed to be the main pattern for representation. Firstly, the technology shall be gradually more mature in order to lay a foundation for the socialized video advertisement. Secondly, considering 
the changes in the media use habit of consumers, we shall carefully use various media resources. The enterprise is required to break the original pattern of TV, PC terminal for information transmission, integrate and innovate the video content, and release the content products attractive to the consumers in their fragmented periods. In terms of the information transmission, the consumers are the accepters, producers and deliverers at the same time. The quality of UGC content produced by consumers is improving by days, which further expands the potential growth space for the brand integration.

\section{Summary}

Elites and ordinary people bring their enthusiasm to join the feast of socialized media. As the magnificent all-people writing becomes a fashion, it has also formed an essential power. The information circulation, influence of public opinion, enormous explosive power of information and such a large popularity it brings are difficult for any print media to achieve. These users keep a close communication with others of the same trade. Apart from the mutual friendly links, they often have many information sharing behaviors such as topic discussion, article reprint, picture comment and video sharing, so the socialized media have the core in a little circle and realize the marketing value of opinion leader based on the Focus Media.

The social communication media have permanently changed the communication pattern among people, but the social communication media still cannot satisfy the demands of all the consumers. The enterprise with innovative spirit shall fully take advantages of the social communication media to listen carefully to the demands of consumers, deeply communicate with them and use the best brand marketing scheme to comprehensively meet their demands.

\section{References}

1. Li, F. The Changes in Consumer Behaviors in Large Data Ara and Its Influence on the Reform of Commercial Mode [J]. Chinese Circulative Economy, 2014, 10: 87-91.

2. Ma, T.L. Preliminary Analysis on the Consumer Behaviors in Group Purchase Website under O2O Mode and Strategies [J]. Modern Business, 2014, 34: 56-57.

3. Ma, Z.P. Research on the Brand Marketing Strategy Based on Consumer Behavior--taking the mobile phone industry as an example [J]. Chinese Collective Economy, 2014, 15: 67-68.

4. Wang, T.L., Zhang, J.Y., Niu, Y.F. Strategy of Improving the Dynamic Competitiveness for Enterprises Based on Network Consumers Behavior [J]. Business Ara, 2014, 13: 56-58.

5. Liu, T.M., Sun, J. Research on the Factors that Affect the Behavior of B2C Electronic Business Consumers [J]. Chinese Market, 2014, 10: 67-68.

6. Chen, J. Research Progress and Prospect of Chinese Consumers Behavior [J]. Chinese Market, 2014, 27: 30-32. 